\title{
Antiamoebic Activity of Marine Sponge Spongia officinalis var. ceylonensis Dendy
}

\author{
Vijai Lakshmi $^{1}$ and Sheela Ghosal ${ }^{2}$ \\ ${ }^{1}$ Medicinal and Process Chemistry Division, Lucknow-226001, India \\ ${ }^{2}$ Microbiology Division, Central Drug Research Institute, Lucknow-226001, India
}

\begin{abstract}
Human amoebiasis due to infection by Entamoeba histolytica is mainly associated with morbidity thus affecting the quality of life and pace of developmental activities of countries with warm climatic conditions. A consistently high global incidence of this disease has been reported. In an endeavor to identify novel molecules with potent antiamoebic activity and lower side-effect, the present study was designed to investigate antiamoebic activity in Spongia officinalis extracts/fractions followed by isolation and characterization of bioactive molecules. The methanol extract of the $S$. officinalis showed promising in vitro and in vivo antiamoebic activity. On further fractionation, the activity was localized in the $n$-butanol soluble fraction from which the major purified fraction was identified as a mixture of alkaloids (xestospongins and araguspongins) by LCMS studies of the $n$-butanol soluble fraction.
\end{abstract}

Key words: Antiamoebic activity, alkaloids, in vitro and in vivo, marine sponge, Spongia officinalis

\section{Introduction}

Human amoebiasis due to Entamoeba histolytica infection is mainly associated with morbidity thus affecting the quality of life and pace of developmental activities of countries with warm climatic conditions. A consistently high global incidence of this disease has been reported from surveys carried out at different intervals of time (Thomas et al., 2010). This disease also possesses a challenge to our national medical and health programmes. A number of therapeutic agents possessing potent in vitro action against trophozoites of E. histolytica have been used to combat this disease. So far, these have been found to be too toxic or providing only symptomatic relief. Leads to obtain novel molecules with antiamoebic activity have been obtained from natural products, either terrestrial plants or marine organisms. Marine sponges are incredible source of novel pharmacologically active compounds (Thomas et al., 2010) which have earlier shown potent efficacy against various diseases. They are known to possess diverse pharmacological activity in several diseases such as cancer, neurodegeneration, type-2diabetes, fungal and microbial infections (Bhosale et al., 1999; Dembitsky et al., 2005; Rao et al., 2006; Coello et al., 2009; Guzmán et al., 2011; Takei et al., 2010). These biological activities have been attributed to the presence of novel sterols, metabolites including steroids, terpenoids, alkaloids, cyclic peptides and unsaturated fatty acids (Litchfield et al., 1976; Findlay and Patil, 1985; Elenkov et al., 1999). With a view to explore the possibilities of finding new molecules with proven therapeutic efficacy for human use, a programme is operational at the Central Drug Research Institute, Lucknow, India for screening of extracts of marine organisms for a wide range of biological activities. The programme consists of collection, identification and extraction of marine flora and fauna along the Indian coasts for biological screening. Spongia officinalis was selected for detailed chemical and biological investigations with a view to isolate bioactive compounds.

$S$ officinalis var. ceylonensis Dendy belongs to the Phylum Porifera, Class Demospongiae and Family Spongiidae. Sponges are utilized as therapeutic agents. A literature search revealed that few compounds have been reported from $S$. officinalis, including alkaloids and steroids (Lin et al., 2003; Lin et al., 2001; Thale et al., 2002; Orabi et al., 2002; Edrada et al., 2002; Williams et al., 2002; Bohlin et al., 1980).

Correspondence to: Vijai Lakshmi, Present address: Department of Biochemistry, King George Medical University, Lucknow, India. E-mail: vijlakshmius@yahoo.com; Phone: +91-(0522)- 2254604 


\section{Materials and Methods}

Collection of marine animals: S. officinalis var. ceylonensis collected from the Ramnad of the Tamil Nadu coast of India in the month of November. A specimen has been preserved in the herbarium of the Botany Division of the Institute with the specimen number 412 .

Extraction, fractionation, and isolation of pure compounds: The freshly collected marine sponges $S$. officinalis $(2.0 \mathrm{~kg})$ were thoroughly washed with distilled water to remove extraneous materials and filled in steel containers and soaked in methanol. This was then transported to the laboratory of Central Drug Research Institute, Lucknow, India. The methanol extract was drained off and the animals were chopped into small pieces and filled in a glass percolator soaked in methanol and left for $24 \mathrm{~h}$ at room temperature. The process of extraction was repeated four times and the combined percolates were concentrated under reduced pressure below $50{ }^{0} \mathrm{C}$ in a rotavapor to provide a green viscous mass. It was further dried under high vacuum for two hours to remove last traces of the solvent (weight $40.0 \mathrm{~g}$ ). A portion of the crude extract $(25.0 \mathrm{~g})$ was fractionated into four fractions by macerating with $n$-hexane, chloroform, and $n$-butanol successively. The $n$-hexane $(0.45 \mathrm{~g})$, chloroform (2.25 g), and $n$-butanol (4.25 g), materials along with $n$-butanol insoluble ( $18.0 \mathrm{~g})$ fractions (Fig.1) were evaluated for antiamoebic activity by in vitro model. The maximum antiamoebic activity was localized in the $n$-butanol soluble fraction. It was analyzed by LCMS and xestospongins and araguspongins were identified as major compounds (Venkateshwarlu et al., 1994). Sepaction and purification of the pure compounds is in progress and will be reported separately.

\section{Test models and methodology for antiamoebic activity}

In-vitro model: Axenic culture of E. histoyitica (200: NIH) maintained TYI-S-33 medium (Diamond et al., 1978) has been used for in-vitro screening. Xenic culture 2771 isolated from an acute case and maintained in Robinson's medium (Robinson, 1968) was used to produce experimental caecal amoebiasis in rats.

Evaluation of in vitro amoebicidal activity: The stock solution of the test agent is prepared by adding small quantity of DMSO and required amount of water. Further serial double dilutions were prepared using triple glass distilled water. Amoebic inoculum $(0.1 \mathrm{ml})$ containing approximately 2000 trophozoites were added to the cavities of shallow cavity slides to which the test sample $(0.1 \mathrm{ml})$ in its required dilution was added. Each cavity was then sealed with cover slip. The slides were kept in the moist chamber at $37^{\circ} \mathrm{C}$. Observations were made at 24 and $48 \mathrm{hrs}$ intervals. The activity of the test agent at the particular dilution was related with cent percent mortality. Metronidazole was the standard compound used. Duplicate sets were kept for each dilution (Das, 1975)

\section{Antiamoebic in-vivo test model}

Experimental production of caecal amoebiasis of rats: Rats were fed on autoclaved rice diet for seven days prior to infection. The caecal contents of these rats attained a $\mathrm{pH}$ of 5.5 to 7.0 without the occurrence of free ammonia which is toxic to these amoebae (Prasad and Bansal, 1983; Leitch, 1988) thus aiding in the consistent production of caecal infection. Rats under ether anesthesia were inoculated intracaecally with 0.2 to $0.3 \mathrm{ml}$ of amoebic inoculum containing $10 \times 10^{4}$ trophozoites of $E$. histolytica and the abdominal lesion sutured. After $48 \mathrm{hr}$ the infected rats were ready for therapeutic evaluation of test agents as trophozoites of E. histolytica were visible microscopically in the contents and scrapings of the caecal wall. The animals were divided into two groups. One group was given oral administration of the drug, while the other group served as control group.

Treatment schedule: The test material was suspended in gum acacia suspension in distilled water. The rats were orally administered with the test agent at (900) $\mathrm{mg} / \mathrm{kg}$ b.w. with the help of a feeding needle once daily for five consecutive days. The rats were sacrificed $48 \mathrm{hr}$. after the last dose of test material with an overdose of ether anesthesia and the caecum examined for trophozoites of E. histolytica. The reported method of Neal (1951) was used to evaluate the degree of infection.

\section{Results and Discussion}

The effects of S. officinalis extracts on trophozoites of $E$. histolytica in vitro and against caecal amoebiasis of rats have been summarized in Table 1 . In vitro efficacy was recorded for all the test samples. The in vivo therapeutic efficacy of the crude extracts presented interesting results. It was observed that the methanol extract when administered at a dose of $250 \mathrm{mg} / \mathrm{kg}$ body weight for five days effected $100 \%$ cures. The $n$-butanol and aqueous 
fractions of the same extract exhibited high efficacy with $100 \%$ cures at $100 \mathrm{mg} / \mathrm{kg}$ dose b.w. (Table 1 ).

It is not uncommon that marine organisms possess activity against pathogenic bacteria, fungus and protozoa. The terpenoids isolated from Pseudoplenauria wagenaari possesses antiamoebic activity in vitro model. Lobane diterpene derivatives of this organism were active against phytopathogenic fungus, Cladosporium cucumerinum, gram positive bacteria, Bacillus subtilis, and yeast, Saccharomyces cerevisiae (Edrada et al., 1998). Similar derivatives have also been isolated from other marine organisms (Shin and Fenical 1991).

Table 1. Results of antiamoebic activity of Spongia officinalis var. ceylonensis Dendy against $E$. histolytica in in-vitro and in-vivo models.

\begin{tabular}{|c|c|c|c|c|}
\hline \multirow{3}{*}{ Name of the exts./frs. } & \multicolumn{4}{|c|}{ Antiamoebic activity against $E$. histolytica } \\
\hline & \multirow{2}{*}{$\begin{array}{l}\text { In- vitro } \mathrm{MIC} \\
(\mu \mathrm{g} / \mathrm{ml})\end{array}$} & \multicolumn{3}{|c|}{ In-vivo } \\
\hline & & Dose & $\mathrm{mg} / \mathrm{kg}$ (for 5 days) & $\%$ Inhibition \\
\hline Methanol ext. & 31.25 & & 250 & 100 \\
\hline 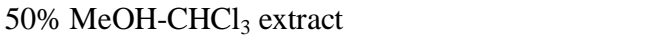 & 125 & & 250 & 20 \\
\hline Hexane sol. fraction from methanol extract & 125 & & 100 & 25 \\
\hline Chloroform soluble fraction from the methanol ext & 125 & & 100 & 30 \\
\hline$n$-Butanol soluble fraction of the methanol ext & 31.25 & & 100 & 100 \\
\hline Aqueous fraction of the methanol extract & 31.25 & & 100 & 100 \\
\hline Metronidazole & 10 & & 50 & 60 \\
\hline (Standard) & & & 100 & 100 \\
\hline
\end{tabular}

Chopped Spongia officinalis (Fresh) $2.0 \mathrm{~kg}$

Extd. with $\mathrm{MeOH}$

$(10$ lit $\times 4)$, filtered and

concentrated

MeOH ext.

(weight 40.0 g)

Active (in vitro)

(Antifungal and antibacterial)

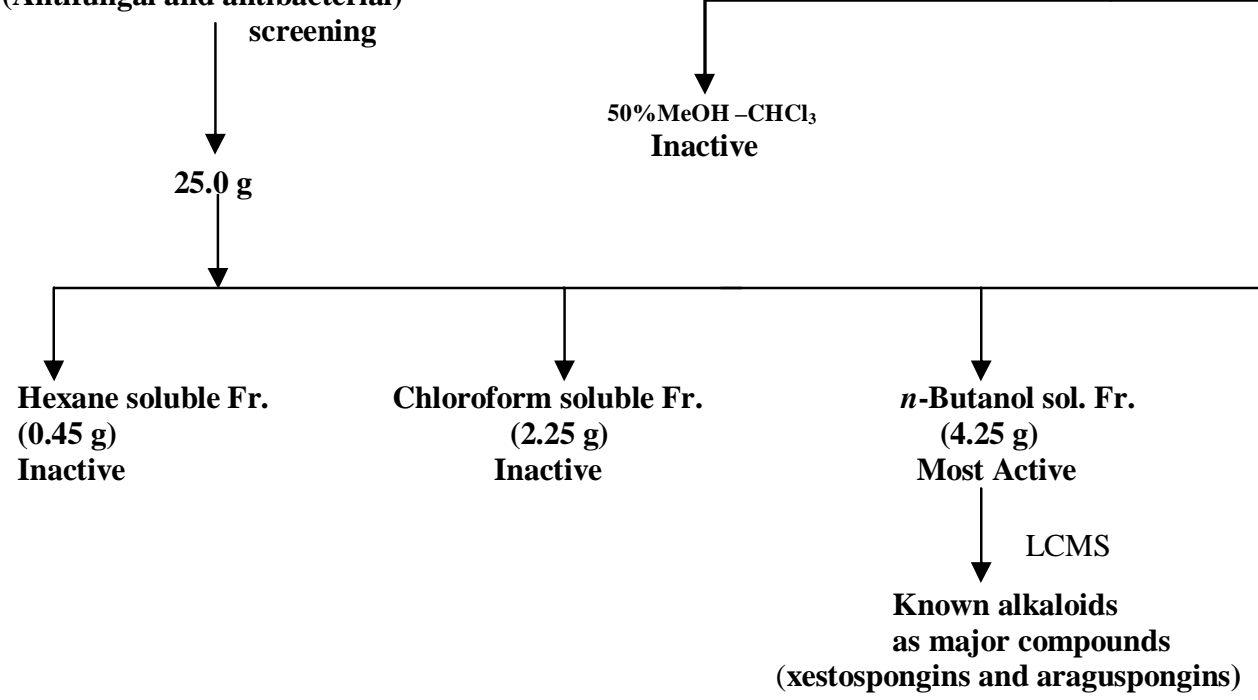

Residual animal

(rejected)

Figure 1. Isolation of bioactive compounds from S. officinalis 
In view of the results presented, it is evident that marine organisms can provide leads for antiamoebic agents in future. Thus, the ocean with its innumerable biota offers a challenge to both chemists and biologists alike as it is a large reservoir of novel chemical entities with therapeutic potential for human use.

The results assumed significance when viewed regarding the condition of the caecal wall. The caecum of rats receiving the crude extract and the $n$-butanol soluble fraction appeared normal with thin caecal wall comparable to the rats treated with the standard drug metronidazole (100mg/kg body weight). However, the caecal contents of the rats treated with the test agents although being normal was slightly less formed as compared to the metronidazole treated rats. The results become still more interesting when the caecum of the treated rats were compared with the untreated rat caecum which is shapeless with ulcers on the walls and with mucous and very little faecal matter as contents.

It is apparent from the results that $S$. officinalis possessed significant amoebicidal activity against $E$. histolytica. In the present study, the active fractions possessed $100 \%$ activity at $100 \mathrm{mg} / \mathrm{kg}$ dose for 7 days has been identified. Development of these fractions into a viable drug requires further isolation of active molecules from these fractions and structural characterization of the active compounds are being pursued in our laboratory and will be reported later. This validates the promise held by the ocean as a source of therapeutic agents against human ailments.

\section{Declaration of interests}

All the authors have no conflict.

\section{Acknowledgements}

We are grateful to the Ministry of Earth Sciences, Government of India for providing financial assistance. We are also thankful to Head, HRDG CSIR, Government of India, New Delhi for grant of Emeritus scientistship to VL, which enabled us to compile these research findings. We are thankful to the Director CSIR-CDRI, Lucknow, India for providing necessary research facilities as well as his keen interest in marine natural products. We are also grateful to Dr. M.N. Srivastava for collection of the sponge. We also acknowledge the SAIF for spectral data.

\section{References}

Bhosale, S.H., Jagtap, T.G., Naik, C.G. 1999. Antifungal activity of some marine organisms from India, against food spoilage A. spergillus strains. Mycopathologia 147, 133-138.

Bohlin, L., Gehrken, H.P., Scheuer, P.J., Djerassi, C. 1980. Minor and trace sterols in marine Invertebrates. XVI. 3Hydroxymethyl-A-nor-5-gorgostane, a novel sponge sterol. Steroids 35, 295-304.

Coello, L., Martín MJ, Reyes, F. 2009. 1,5Diazacyclohenicosane, a new cytotoxic metabolite from the marine sponge Mycale sp. Mar. Drugs 7: 445-450.

Das, SR. 1975. A novel and rapid method for in vitro testing of antiamoebic agents against aerobic and anaerobic amoebae growing axenically or with bacteria, Curr. Sci. 44: 463-464.

Dembitsky, V.M., Gloriozova, T.A., Poroikov, V.V. 2005. Novel antitumor agents: marine sponge alkaloids, their synthetic analogs and derivatives. Mini Reviews Med. Chem. 5, 319336.

Diamond, L.S., Harlow, D.R. \& Cunnick, C.C. (1978). A new medium for the axenic cultivation of Entamoeba histolytica and other Entamoeba. Trans. R. Soc. Trop. Med. Hyg. 72, 431-432.

Edrada, R.A., Heubes, M., Brauers, G., Wray, V., Berg, A., Graefe, U., Wohlfarth, M., Muehlbacher, J., 2002. J. Nat. Prod. 65, 1598-1604.

Edrada, R.A., Proksh, P., Wray, V., Wilte, L. and Ofrogen, L.V. 1998. Four new bioactive lobane diterpenes of the soft coral Lobophytum paucifolrum from Mindoro, Phillipines, J. Nat. Prod. 61, 358-361

Elenkov, I., Popov, S., Andreev, S. 1999. Sterols from two black sea sponges (Haliclona p.). comparative biochemistry and physiology. Part B, Biochem. Mol. Biol. 123, 357-360.

Findlay, J.A., Patil, A.D. 1985. Novel sterols from the finger sponge Haliclona oculata. Can. J. Chem. 63, 2406-2410.

Guzmán, E.A., Johnson, J.D., Linley, P.A., Gunasekera, S.E., Wright, A.E. 2011. A novel activity from an old compound: Manzamine A reduces the metastatic potential of AsPC-1 pancreatic cancer cells and sensitizes them to TRAILinduced apoptosis. The J. New Anticancer Agents. 29, 777785 .

Leitch, GJ. 1988. Intestinal luminal and mucosal microclimate $\mathrm{H}^{-}$and $\mathrm{NH}^{+}$concentration as factors in the etiology of experimental amoebiasis. Am. J. Trop. Med. Hyg., 38, 480 496. 
Lin, W., Brauers, G., Ebel, R., Wray, V., Berg, A.S., Proksch, P. 2003. Novel chromone derivatives from the fungus Aspergillus versicolor isolated from the marine sponge Xestospongia exigua. J. Nat. Prod. 66, 57-61.

LinWH, Li J, Fu H Z, Proksch, P. 2001. Four novel hydropyranoindeno derivatives from marine fungus Aspergillus versicolor. Chin. Chem. Lett. 12, 435-438.

Litchfield, C., Greenberg, A.J., Noto, G., Morales, R.W. 1976. Unusually high levels of C24-C30 fatty acids in sponges of the class Demospongiae. Lipids 11, 567-570.

Neal, R.A. 1951. Some observations in the variations of virulence and response to chemotherapy of strains of Entamoeba histolytica. Trans. Roy. Soc. Trop. Med. Hyg. 44, 439-452.

Orabi, K.Y., Sayed, E. 1., Khalid, A., Hamann, M.T., Dunbar, D.C., Alsaid, M.S., Higa, T., Kelly, M. 2002. Araguspongines, K. and L, new bioactive bis-1oxaquinolizidine N-oxide alkaloids from Red Sea specimens of Xestospongia exigua. J. Nat. Prod. 65, 17821785 .

Prasad, K.B.N. and Bansal, I. 1983. Interrelationship between faecal $\mathrm{pH}$ and susceptibility to Entamoeba histolytica infection of rats. Trans. Roy. Soc. Trop. Med. Hyg. 77, 271274.

Rao, K., Donia, M., Peng, J., Garcia, E., Palomero, D., Alonso, A., Martinez, M., Medina, S., 2006. Tropical parasitic, and Alzheimer's diseases. J. Nat. Prod. 69, 1034-1040.
Robinson, G.R. 1968. Laboratory cultivation of some human parasitic amoeba. J. Gen. Microbiol. 53, 19-29.

Shi, J., Fenical, W. 1991. Fucoside A-D anti-inflammatory diterpenoid glycoside of new structural classes from the Caribbean gorgonian Eunacea fusca. J. Org. Chem. 56, 3153-3158.

Takei, M., Umeyama, A., Shoji, N., Hashimoto, T. 2010. Polyacetylenediols regulate the function of human monocyte-derived dendritic cells. Int. J. Immunopharmacol. 10, 913-921.

Thale, Z., Johnson, T., Tenney, K., Wenzel, P.J., Lobkovsky, E., Clardy, J., Media, J., Pietraszkiewicz, H., Valeriote, F.A., Crews, P. 2002. Structures and cytotoxic properties of sponge-derived bisannulated acridines. J. Org. Chem. 67, 9384-9391.

Thomas, T.R.A., Kavlelar, D.P., Loka, Bharti, P.A. 2010, Marine drugs from sponge-microbe association - a review. Marine Drugs. 8, 1417-1468.

Venkateshwarlu, Y., Reddy, M.V.R., Rao, J.V. 1994. Three new heptaprenyl hydroquinone derivatives from the sponge Ircinia fasciculata. J. Nat. Prod. 57, 1286-1289.

Williams, D.E., Craig, K.S., Patrick, B., McHardy, L.M., Van, S.R., Roberge, M., Andersen, R. J. 2002. Motuporamines, anti-invasion and anti-angiogenic alkaloids from the marine sponge Xestospongia exigua (Kirkpatrick), isolation, structure elucidation, analogue synthesis, and conformational analysis. J. Org. Chem. 67, 245-258. 